\title{
Thai generic-brand dry canine foods: mutagenicity and the effects of feeding in vivo and in vitro
}

\author{
Tanyalak Khuntamoon ${ }^{1}$, Apanchanid Thepouyporn ${ }^{1}$, Sarunya Kaewprasert ${ }^{1}$, Pattaneeya Prangthip ${ }^{1}$, \\ Somchai Pooudoung ${ }^{1}$, Urai Chaisri ${ }^{2}$, Phudit Maneesai ${ }^{3}$ and Karunee Kwanbunjan ${ }^{1 *}$
}

\begin{abstract}
Background: The commercial pet-food industry and the market value of the pet industry have increased. Most owners are concerned about their pets' health, and prefer commercial pet foods as their regular diet. This study thus aimed to determine whether a selection of local generic-brand dry canine foods had any potential to promote chronic disease.

Methods: Five local, generic-brand, dry canine foods were studied for potential mutagenicity; the effects of long-term consumption were also observed in rats. All canine foods were extracted with distilled water and absolute ethanol. The Ames test was used to detect short-term genetic damage, using Salmonella typhimurium tester strains TA98 and TA100. Simultaneously, the long-term effects were studied in an animal model by observing rats fed with these canine foods, compared with normal rat food, for a period of 15 weeks.

Results: Using the water extracts, all dry canine foods studied showed considerable mutagenic effects on the tester strains. One brand affected both tester strains, whereas 3 showed positive to TA98, and one to TA100. With the absolute ethanol extract, three of the five brands had a considerable mutagenic effect on TA98, and another affected TA100. In the long-term test, all rats remained alive until the end of the experiment, exhibited no apparent signs of toxicity or serious illness, and maintained normal bodyweight and weight gain. Serum blood biochemistry and hematological parameters in canine food-fed rats showed some negative effects. Correspondingly, histopathological investigation of their liver and kidneys showed deterioration.
\end{abstract}

Conclusions: Mutagenic potential and the negative potential health impacts were observed in all local-brand dry canine foods tested.

Keywords: Dry canine foods, Mutagenicity, Long-term consumption

\section{Background}

Dietary consumption is closely related to the development of many chronic diseases, such as obesity, cardiovascular disease, chronic renal disease, and cancer. Although the dietary mechanism related to some diseases is not clear, healthy food behaviors in aging animals can reduce the risk of many chronic diseases. Obesity is the most common form of malnutrition among dogs, estimated at $24-34 \%$ in the United States (US) [1].

\footnotetext{
* Correspondence: karunee.kwa@mahidol.ac.th

'Department of Tropical Nutrition and Food Science, Faculty of Tropical

Medicine, Mahidol University, Bangkok 10400, Thailand

Full list of author information is available at the end of the article
}

Obesity is a preventable health hazard, with health implications such as cancer, type-2 diabetes mellitus, cardiovascular complications, and decreased lifespan [2]. Most obesity cases are due to overeating and lack of exercise; this is true for both dogs and people [3]. An estimated $0.5 \%$ of dogs in the US are diabetic; and the vast majority of these are either overweight or obese [4]. Metabolic studies from $\mathrm{He}$ et al. [5] indicated that obese pigs had higher serum insulin and glucagon that led to insulin resistance and dyslipidemia, similar to observations in other obese species such as rats, mice, rabbits, and human children and teenagers. 
Cancer is one of the most common non-accidental causes of death for dogs and cats [6]. While the increasing prevalence of cancer among pets is multifactorial, it is also related to pets living longer. Numerous studies have outlined risk factors of certain nutrients and their relationships to the development of cancer in humans, such as decreased fiber and increased fat, which are commonly indicated as causal factors for a wide variety of malignant conditions of the gastrointestinal tract, breasts, and bladder. A study by Sonnenschein et al. [7] suggested that nutritional factors resulting in altered body composition early in life might be important in dog breast cancer.

The commercial pet-food industry is changing continuously, and the market value of the pet industry has increased from approximately 15 million US dollars in 1992 [8], to around 300 million US dollars in 2011 [9]. Most owners are concerned about their pets' health, and prefer commercial pet foods as their regular diet. These foods are recognized as being nutritious, convenient, and of consistent quality. However, there are reasons to be concerned about the raw materials used for pet food production. For example, increased oral intake of fat, monosodium L-glutamate, and ursolic acid may introduce significant alterations in the composition of gut microbiota, which are thought to play an important role in amino acid [10], and lipid metabolism [11]. The objective of this study is to determine the safety of pet foods currently available in the market, in light of the increasing incidence of chronic diseases in pets due to their food intakes. This preliminary study could inform pet owners' selection of appropriate diets for their pets, and the petfood industry, potentially significantly improving the standards of companion animal health in Thailand.

\section{Methods}

\section{Study design}

Canine food

Five commonly consumed, locally manufactured, commercial dry canine foods were purchased from a market, sufficient for short-term testing and for a longer feeding experiment. For the purposes of this study, the foods were named DG diet, AP diet, AL diet, RS diet, NT diet (Table 1), and these canine foods shared the major part of the market because of their economical price. All five pet diets were extracted in crude distilled-water and absolute-ethanol and using Ames test to determine mutagenic potential.

\section{Mutagenicity assay}

The Ames assay was used with $S$. typhimurium strains TA98 and TA100, and the well-known plateincorporation procedure described by Maron and Ames [12]. The histidine-dependent (His-), bacterial tester strains TA98 and TA100 are capable of detecting frameshift mutation and base-pair substitute mutation, respectively. They are designed to contain a mutation in their histidine operon. Since the bacterial tester plates contain histidine deficient media TA98 and TA100 colonies normally cannot develop. Those bacterial colonies that do survive can only do so through reverse mutation, thus indicating probable mutagenesis. Both tester strains were kindly provided by Professor BN Ames, University of California at Berkeley, California, USA through the National Cancer Institute Thailand.

The testing samples generate mutagenicity by inducing reverse mutation in the tester strains during plate incorporation assay according to their mutagenic potential. The number of revertant colonies was counted. All cultures were made in triplicate. The absence of toxicity was examined by observing background bacterial growth, which would normally be present. The positive controls were 4-nitroquinoline 1-oxide (NQO) at a concentration of $21.04 \mu \mathrm{mol} / \mathrm{L}$ for TA98, and 10.52 $\mu \mathrm{mol} / \mathrm{L}$ for TA100, Aflatoxin B1 $\left(\mathrm{AFB}_{1}\right)$ at a concentration of $0.96 \mu \mathrm{mol} / \mathrm{L}$ for TA98 and TA100, and benzo(a)pyrene $(\mathrm{B}(\mathrm{a}) \mathrm{P})$ at a concentration of $396.33 \mu \mathrm{mol} / \mathrm{L}$ for TA98 and $198.16 \mu \mathrm{mol} / \mathrm{L}$ for TA100. The negative controls were distilled water and Dimethyl sulfoxide

Table 1 Nutritional fact of five canine foods and rat food

\begin{tabular}{|c|c|c|c|c|c|c|}
\hline Nutritional facts Garanteed analysis & Control diet (Rat food) & DG diet & AP diet & AL diet & RS diet & NT diet \\
\hline Protein (Min) \% & 24 & 22 & 27 & 27 & 26 & 26 \\
\hline Fat (Min) \% & 4.5 & 9 & 8 & 13 & 8 & 8 \\
\hline Ash (Max) \% & & 10 & & & & \\
\hline Calcium (Min) \% & 1 & 1 & 1.5 & & 1.2 & \\
\hline Phosphorus (Min) \% & 0.9 & 0.8 & 1.25 & & 1 & \\
\hline Fiber (Max) \% & 5 & 4 & 4 & 3.5 & 4 & 4 \\
\hline Moisture (Max) \% & 12 & 10 & 10 & 9.5 & 10 & 10 \\
\hline Manufacturer & S.W.T. & Petech & S.W.T. & Nutrix & Betagro & Betagro \\
\hline Lot No. & EQFD082 & Stn029041104 & S2Ex5 & 8100239 & $1 / 803109$ & 1/711071 \\
\hline
\end{tabular}


(DMSO), as they represented the solvents to remove different substance groups in pet foods.

The mutagenicity of the test specimens was assessed by looking at the increase in His + revertants, to at least 20-50 revertant colonies/plate for TA98, and 120-200 revertant colonies/plate for TA100. A test sample produced a positive dose-response relationship over 3 concentrations, with the highest increase not less than twice the negative control value. The trace of histidine on the surface of the agar allowed all the bacteria on the plate to undergo several divisions and produce a faint background lawn, which could be seen under a dissecting microscope. The background lawn is essential to the test as an indicator of growth caused by the toxicity of the test sample. If massive cell deaths occur, defined as the killing effect or partial killing effect, the background lawn on the test plate will be sparse compared with the control plate. In this case, more histidine is available to the surviving bacteria, which undergo more cell divisions and may appear as small colonies, which could lead to false positive results.

\section{Long-term controlled experimental trial}

We used rats to test the long-term effects of the food. A dog's lifespan is relatively long. The lifespans of rats and dogs are 2-4 and 10-16 years, respectively Compartively, the weaning age for a rat is about 3 weeks (6 weeks for a dog). The experiment started at about 9 weeks of age, or an equivalent 16-20 weeks for a dog. The duration of the study (90 days) was equivalent to $12 \%$ and $2.5 \%$ of the mean lifespan for a rat and a dog, respectively [13].

\section{Housing}

The animal-experimentation protocol was approved by the Ethics Committee of the Faculty of Tropical Medicine-Animal Care and Use Committee. Male Wistar rats with 150-200 g body weight were supplied by the National Laboratory Animal Center, Mahidol University, Salaya Campus, Nakhon Pathom, Thailand. The rats were housed individually in cages in a temperature-controlled room at $25 \pm 2{ }^{\circ} \mathrm{C}$ with a 12 -h light-dark cycle (light on at 6:00 am). All animals were allowed to acclimatize for 2 weeks in the Laboratory Animal Unit of the Faculty of Tropical Medicine, Mahidol University, where they were fed with standard commercial food and distilled water ad libitum. Prior to oral subchronic toxicity testing, they were fasted for $16 \mathrm{~h}$ and allowed free access to water. The average body weight of the rats at day 0 of the experiment was $310.6 \mathrm{~g}$.

\section{Data collection}

Blood samples were drawn by tail-vein puncture or section every 4 weeks. Hematological analyses of 12 basic parameters were performed by Hemavet (Drew Scientific, Inc.). Blood chemistry was analyzed by the Liasys Analyzer Medical System (AMS) (Rome, Italy), including blood urea nitrogen (BUN), creatinine (CR), aspartate aminotransferase (AST), alanine aminotransferase (ALT), cholesterol (CHOL), triglyceride (TG), and one mineral, phosphorus (P). At the end of the test, after final blood sampling, the rats were euthanized with $10 \mathrm{mg} / \mathrm{kg}$ xylazine and 50-70 $\mathrm{mg} / \mathrm{kg}$ ketamine i.p. Histopathological analysis was in additionally carried out on the liver and kidneys as well as other vital organs such as heart, lung and brain and recorded as lesions under a light microscope after processing in buffered formalin fixation, paraffin embedding, and hematoxylin and eosin stain. The microscopic appearances were recorded.

\section{Statistical analysis}

ONE-WAY ANOVA followed by a Least Significant Different (LSD) and Chi-square test using SPSS version 11.0 for Windows were used to analyze resultants.

\section{Results}

The Ames test findings for the water-extracted diets are shown in Table 1. Mutagenicity was found in all diets under differing conditions. The DG diet was dose-dependent for TA100 in the absence of S9, at a $20 \mathrm{mg} / \mathrm{plate}$ and higher concentrations. The AP, AL, and NT diets were positive to TA98, with AP found in the presence of the $\mathrm{S} 9 \mathrm{mix}, 20$ and $30 \mathrm{mg} /$ plate, but not in the AL diet in the absence of the S9 mix, $20 \mathrm{mg} /$ plate. The NT diet was positive in the absence of the S9 mix at $10-20 \mathrm{mg} / \mathrm{plate}$, and with the $\mathrm{S} 9$ mix at $10 \mathrm{mg} /$ plate. The RS diet extract was positive in both tester strains to TA98 without the S9 mix at 5,10 , and $20 \mathrm{mg} /$ plate, and with the $\mathrm{S} 9 \mathrm{mix}$ at 20 and $40 \mathrm{mg} /$ plate, as well as TA100 at $30 \mathrm{mg} /$ plate with the S9 mix. All diets showed partial killing in both tester strains at different concentrations. Diets DG, AP, and NT also exhibited killing effects.

Table 2 shows that the dry-food ethanol extracts were more toxic to the tester bacteria at high concentrations. A partial killing effect with both strains was observed in the absence of the S9 mix at concentrations of 5 and 10 $\mathrm{mg} /$ plate, and the presence of S9 mix at 7.5 and $10 \mathrm{mg} /$ plate with the DG diet extract, but no mutagenicity was found. In the AP, AL, RS, and NT diets, dose-dependent mutagenicity was found in different concentrations and S9-mix tests. Mutagenicity was observed in the AP diet extract for TA98 in the absence of the $\mathrm{S} 9 \mathrm{mix}$, at $1 \mathrm{mg} /$ plate. The AL diet extract produced with TA98 in the absence of the $\mathrm{S} 9 \mathrm{mix}$, at 0.01 and $0.1 \mathrm{mg} /$ plate. The RS diet produced with TA100 in the absence of S9 mix, at 0.5 and $1 \mathrm{mg} /$ plate. The NT diet produced with TA98 in 
Table 2 Mutagenicity of dry canine-food extracts from distilled water with S. typhimurium TA98 and TA100

\begin{tabular}{|c|c|c|c|c|c|}
\hline \multirow[t]{2}{*}{ Sample } & \multirow{2}{*}{$\begin{array}{l}\text { Amount } \\
\text { mg/plate }\end{array}$} & \multicolumn{4}{|c|}{ No. of $\mathrm{His}^{+}$Revertants/plate ${ }^{a}$} \\
\hline & & TA 98, -59 & TA $98,+59$ & TA100, -S9 & TA $100,+59$ \\
\hline \multirow[t]{6}{*}{ DG diet } & 0 & 29.5 & 34 & 110 & 123 \\
\hline & 5 & 42.5 & 49 & 137.5 & 133.5 \\
\hline & 10 & 32 & 55.5 & 181.5 & 173 \\
\hline & 20 & $39^{p}$ & $68^{p}$ & 258.5 & $190.5^{e}$ \\
\hline & 30 & $58^{\mathrm{p}}$ & $70^{\mathrm{p}}$ & $262.5^{p}$ & $235^{\mathrm{P}}$ \\
\hline & 40 & $64.5^{p}$ & $87.5^{p}$ & $283.5^{p}$ & $190^{p}$ \\
\hline \multirow[t]{7}{*}{ AP diet } & 0 & 38 & 32.5 & 112 & 129 \\
\hline & 0.5 & 47 & 55.5 & 100 & 100 \\
\hline & 5 & 48.5 & 57 & 129 & 163 \\
\hline & 10 & 31.5 & 58 & 140.5 & 161.5 \\
\hline & 20 & 39 & 69 & 190.5 & 191.5 \\
\hline & 30 & $42^{\mathrm{P}}$ & 70.5 & $191.5^{p}$ & $205^{e}$ \\
\hline & 40 & $102^{\mathrm{p}}$ & $80.5^{p}$ & $207^{\mathrm{P}}$ & $222^{\mathrm{P}}$ \\
\hline \multirow[t]{6}{*}{ AL diet } & 0 & 26.5 & 34 & 110 & 123 \\
\hline & 5 & 43 & 34.5 & 125.5 & 129 \\
\hline & 10 & 41 & 57 & 135.5 & 140 \\
\hline & 20 & $58^{e}$ & $58.5^{p}$ & 167.5 & 175 \\
\hline & 30 & $38^{\mathrm{p}}$ & $63^{\mathrm{P}}$ & $195^{\mathrm{P}}$ & $261^{p}$ \\
\hline & 40 & $37.5^{p}$ & $43^{p}$ & $189^{\mathrm{P}}$ & $237.5^{p}$ \\
\hline \multirow[t]{7}{*}{ RS diet } & 0 & 26.5 & 42 & 112 & 129 \\
\hline & 0.5 & 37 & 42 & 121 & 142.5 \\
\hline & 5 & 62 & 55 & 150.5 & 183.5 \\
\hline & 10 & 56 & 76.5 & 166 & 177.5 \\
\hline & 20 & 58.5 & 80.5 & $203.5^{p}$ & 212 \\
\hline & 30 & $43^{P}$ & $67.5^{\mathrm{e}}$ & $229.5^{p}$ & $268^{e}$ \\
\hline & 40 & $61.5^{p}$ & $99.5^{\mathrm{e}}$ & $261.5^{p}$ & $297^{P}$ \\
\hline \multirow[t]{5}{*}{ NT diet } & 0 & 29.5 & 34 & 110 & 123 \\
\hline & 5 & 30.5 & 57 & 117.5 & 171 \\
\hline & 10 & 84 & 72 & 162.5 & 177 \\
\hline & 20 & 68.5 & $67.5^{p}$ & $222.5^{p}$ & $224^{p}$ \\
\hline & 30 & $56^{e}$ & $52^{\mathrm{p}}$ & $236.5^{p}$ & $171.5^{p}$ \\
\hline Positive control & Amount/plate & & & & \\
\hline \multirow[t]{2}{*}{ 4-NQO } & $0.2 \mu \mathrm{g}$ & ND & ND & $1040 \pm 113$ & ND \\
\hline & $0.4 \mu \mathrm{g}$ & $195 \pm 1$ & ND & ND & ND \\
\hline \multirow[t]{2}{*}{ BAP } & $5 \mu \mathrm{g}$ & ND & ND & ND & $887 \pm 91$ \\
\hline & $10 \mu \mathrm{g}$ & ND & $523 \pm 4$ & ND & ND \\
\hline AFB1 & $0.03 \mu \mathrm{g}$ & ND & $138.5 \pm 3$ & ND & $387.5 \pm 3$ \\
\hline
\end{tabular}

${ }^{a}=$ Mean of duplicate

$\mathrm{e}=$ effect

$\mathrm{p}=$ partial killing effect

$\mathrm{ND}=$ Not determine

the presence of S9, at $0.5 \mathrm{mg} /$ plate. Partial killing was observed in all diets at different concentrations. Moreover, killing effects were found in the AP-diet extracts.
All rats in both study groups survived the 15-week feeding study. During the experimental period, no significant abnormality in food intake, feces, hair, or 
behavior in any group of animals was observed, with no apparent toxicity. At the start of the investigation, no significant difference was detected between the rats fed with canine food and the control in all hematological indices, except for mean corpuscular volume.

At week 4 of the experimental period, blood parameters in rats fed with 3 diets AP, AL and RS diets) were more elevated, some statistically significantly. These included red blood cells (RBC), hemoglobin $(\mathrm{Hb})$, hematocrit $(\mathrm{Hct})$, mean corpuscular hemoglobin $(\mathrm{MCH})$, mean corpuscular hemoglobin concentration $(\mathrm{MCHC})$, platelets, white blood cells (WBC), and monocytes $(P<0.05)$. At weeks 8 and 15 , most hematological indices of the control group increased sharply, but the level was still not significantly different from the rats fed with canine food. Interestingly, the white blood cell counts of the control group of rats were lower than all drycanine-food groups for all 15 weeks of the experiment. Thus, food quality may affect WBC numbers. In addition, the RBC count for all dry-canine-food groups, and the control group, were higher than the normal range. Thus, blood-sampling site may affect blood concentrations and RBC numbers (Figs. 1 and 2).

In the long-term feeding experiment with dry canine foods, serum cholesterol and TG levels of the experimental groups were slightly higher than the control group, but without statistical significance. Among the rats fed dry canine foods, serum blood chemistry results (BUN, CR, ALT, AST, and phosphorus) were statistically different from the control group. However, these blood parameters were normal, except that BUN was higher than the control rats. Gross examinations of the organs (heart, liver, kidneys, spleen, pancreas, and other internal organs) were conducted at week 15, and no changes in any rat were noted. Histopathologic changes were blindly examined by two independent observers (UC and PP). The liver and kidneys were graded into 5 levels; normal appearance, 0-25\%, 26-51 \%, 51-75\% and $76-100 \%$ tissue degeneration.

As seen in Table 3 and 4, the liver and kidney of all rats fed with dog foods were significantly degenerated $(p<0.05)$ compared to the control group. In agreement with the higher amount of ALT and AST, liver histopathology of all dry-canine-food groups showed irregular phenomena when compared to the control group. Under microscopic examination at 40 times magnification, the livers of control rats were seen to be composed of many individual polygonal hepatocytes with a well defined plasma membrane. There was a normal appearance of space between hepatocyte sinusoids containing a few red blood cells. In contrast, the livers of rats treated with dry canine foods presented marked degeneration of the tissue, especially in the DG diet (Fig. 3). These showed nonspecific areas of hepatocytes with scattered shapes and sizes. The abundant foamy cells (arrow) indicate the fat deposition. The dilation of sinosoids (head arrow) which usually accompanies hypertrophy and hyperplasia, which all caused by tissue injury was also observed.

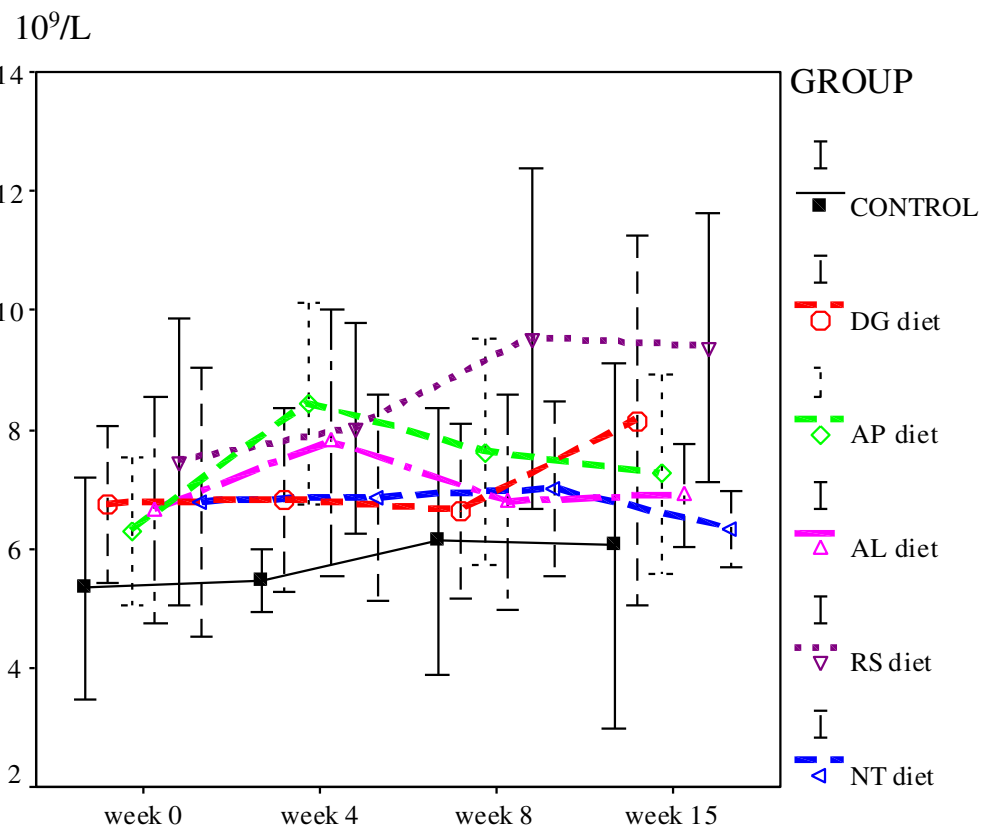

Experimental period

Fig. 1 White blood cell count of rats fed experimental diets from week 0 to week 15 (Normal range between $7.3-12.6 \times 10^{9} / \mathrm{L}$ ) 


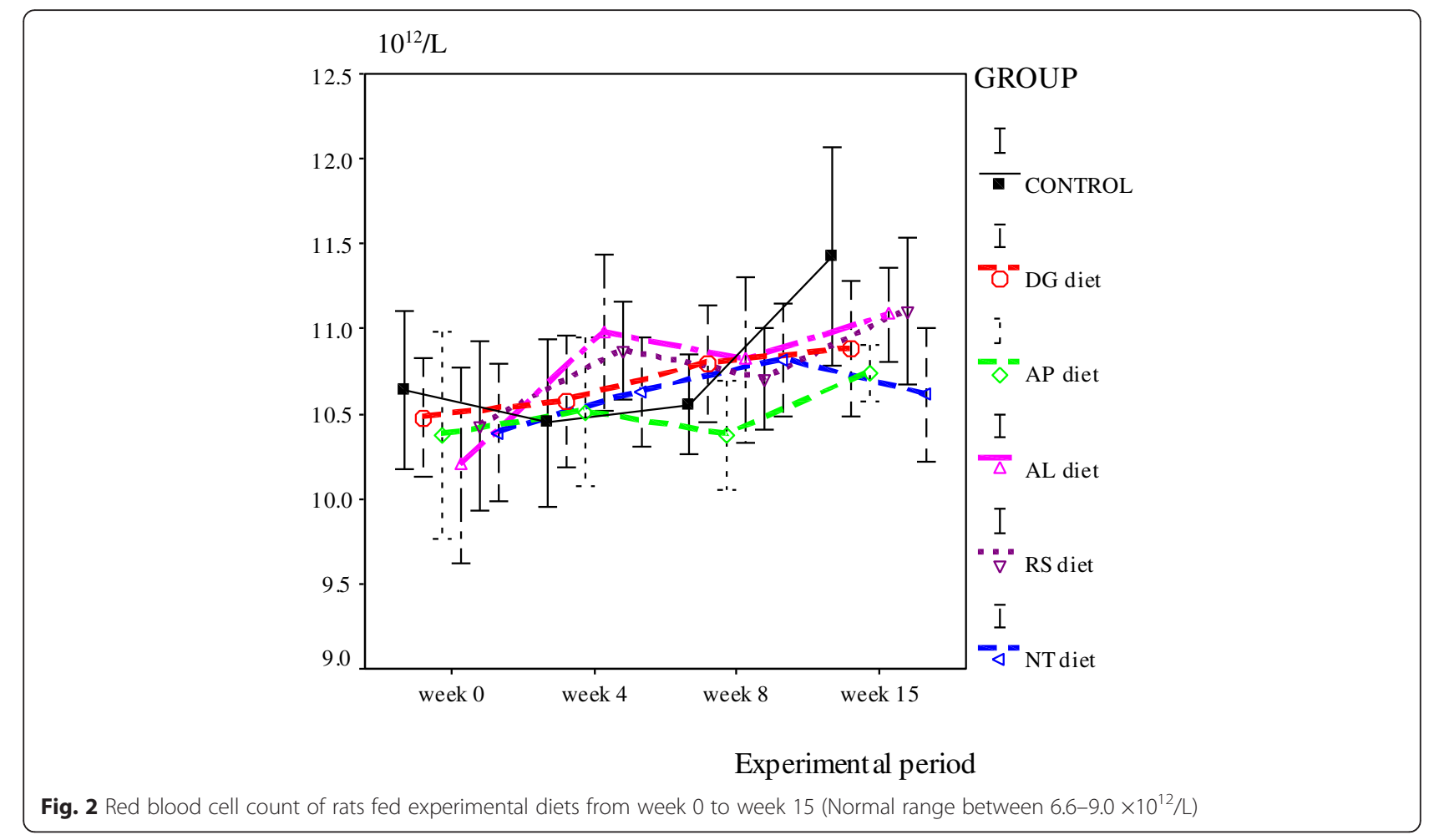

Under light microscopy at 40 times magnification, the illustration of kidney histopathology is also in agreement with the BUN results. The cortical area of the control group displayed a regular round structure of the glomerulus with the continuous layer of Bowman's capsule. The cells of the collecting tubules, proximal convoluted tubules and distal convoluted tubules were intact with distinct cell outlines. However, higher amounts of BUN were seen in all dry-canine-food groups along with the same kidney degeneration, especially in the NT diet (Fig. 4). The epithelial cells of the proximal tubules had degenerated and collapsed into the lumen (arrows). The glomerulus was also found to be congested and atrophied (arrow head), resulting in the loss of reabsorption and filtration functions. No pathological changes appeared in heart, lung and brain.

\section{Discussion}

Short-term tests that detect genetic damage have allowed the carcinogenic risk of chemicals to humans to be evaluated [14]. The Ames assay, which is recommended for testing the mutagenicity of chemical compounds with potential pharmacological applications $[15,16]$ was used in the present study. The mutagenic test used $S$. typhimurium tester strains TA98 and TA100, from two kinds of solvent extracts (distilled water and absolute ethanol). They showed significantly different numbers of induced revertants compared with the control group.
Four of five samples of local-brand dry canine foods extracted by distilled water showed a considerable mutagenic effect on the TA98 strains, which detect frameshift-type mutagens, while two of the samples yielded positive with TA100, a strain that reverts by means of base-pair substitution mutagens. In addition, three samples extracted by absolute ethanol had a considerable mutagenic effect on TA98. Thus, the types of response in different strains clearly differed, revealing significant levels of frameshift-type mutagens in the samples. Frameshift mutations are likely to result in more severe phenotypic effects than many base-change mutations, which result in either silent or conservative changes in protein products [17]. The positive results in our study could be attributed to the extracting agent and the fat content of the pet foods, which affect the properties of the extractor.

Pet-food-extract samples showed mutagenic activity up to a concentration of $20 \mathrm{mg} /$ plate; the highest water-extraction concentration was $40 \mathrm{mg} /$ plate. Water extracts of some dry canine foods at the tested concentrations (up to $50 \mathrm{mg} /$ plate) showed toxicity to the tester strains, with or without a metabolic activator ( $\mathrm{S} 9 \mathrm{mix}$ ). Some ethanol-extracted dry canine food, with or without the $\mathrm{S} 9 \mathrm{mix}$, an antimicrobial effect (toxicity) toward tester strains was also detected when the concentration was $>10$ $\mathrm{mg} /$ plate. According to the results of the toxicity test, the highest concentrations of dry canine food extracts for the mutagenicity assay were selected as $40 \mathrm{mg} /$ plate for water 
Table 3 Mutagenicity of dry canine-food extracts from absolute ethanol with S. typhimurium TA98and TA100

\begin{tabular}{|c|c|c|c|c|c|}
\hline \multirow[t]{2}{*}{ sample } & \multirow{2}{*}{$\begin{array}{l}\text { Amount } \\
\mathrm{mg} / \text { plate }\end{array}$} & \multicolumn{4}{|c|}{ No. of His ${ }^{+}$Revertants/plate ${ }^{a}$} \\
\hline & & TA 98, -S9 & TA 98, +S9 & TA100, -S9 & TA $100,+S 9$ \\
\hline \multirow[t]{7}{*}{ DG diet } & 0 & 32 & 30 & 122 & 110 \\
\hline & 0.1 & 30 & 50 & 91 & 86.5 \\
\hline & 0.5 & 33 & 41 & 129 & 92 \\
\hline & 1 & 36.5 & 52 & 114 & 90.5 \\
\hline & 5 & $19^{p}$ & 44 & $85^{p}$ & 84.5 \\
\hline & 7.5 & ND & $47^{e}$ & ND & $90.5^{\mathrm{e}}$ \\
\hline & 10 & $13.5^{\mathrm{p}}$ & $11.5^{\mathrm{p}}$ & ND & $76.5^{p}$ \\
\hline \multirow[t]{9}{*}{ AP diet } & 0 & 28 & 27 & 137 & 110 \\
\hline & 0.01 & 26.5 & ND & 116 & ND \\
\hline & 0.1 & 25 & 39 & 116.5 & 87 \\
\hline & 0.5 & 29.5 & 38.5 & 84.5 & 90.5 \\
\hline & 1 & 55 & 33 & $61^{p}$ & 87 \\
\hline & 5 & $25.5^{\mathrm{p}}$ & 33.5 & $76.5^{p}$ & 81 \\
\hline & 10 & $26^{\mathrm{p}}$ & $45.5^{\mathrm{p}}$ & $100.5^{p}$ & $103.5^{e}$ \\
\hline & 20 & $31.5^{\mathrm{p}}$ & $30^{p}$ & $86^{p}$ & $100^{e}$ \\
\hline & 30 & $21^{p}$ & ND & $105.5^{p}$ & ND \\
\hline \multirow[t]{7}{*}{ AL diet } & 0 & 28 & 30 & 137 & 110 \\
\hline & 0.01 & 66 & ND & 113 & ND \\
\hline & 0.1 & 63 & 38.5 & 94.5 & 91 \\
\hline & 0.5 & $64.5^{\mathrm{p}}$ & 49 & $83^{p}$ & 103 \\
\hline & 1 & $32^{p}$ & 56.5 & $94.5^{p}$ & 107.5 \\
\hline & 5 & ND & $31.5^{p}$ & ND & 132.5 \\
\hline & 10 & ND & $21^{p}$ & ND & ND \\
\hline \multirow[t]{7}{*}{ RS diet } & 0 & 32 & 26 & 137 & 110 \\
\hline & 0.01 & 27 & ND & ND & ND \\
\hline & 0.1 & 48.5 & 33 & 196.5 & 92 \\
\hline & 0.5 & $31^{p}$ & 42.5 & 307.5 & 126 \\
\hline & 1 & $37.5^{p}$ & 30 & 262.5 & 138.5 \\
\hline & 7.5 & ND & 28.5 & $63^{p}$ & $87.5^{p}$ \\
\hline & 10 & ND & ND & $75^{p}$ & $106.5^{p}$ \\
\hline \multirow[t]{7}{*}{ NT diet } & 0 & 32 & 30 & 108 & 110 \\
\hline & 0.1 & 31.5 & 34.5 & 69.5 & 101.5 \\
\hline & 0.5 & 28.5 & 63 & $78^{p}$ & 84.5 \\
\hline & 1 & 31 & 52.5 & $95.5^{p}$ & 127.5 \\
\hline & 2.5 & 13.5 & 33 & ND & 126 \\
\hline & 5 & $21^{e}$ & $81^{p}$ & ND & $109^{e}$ \\
\hline & 10 & $13.5^{p}$ & $58^{p}$ & ND & ND \\
\hline Positive control & Amount/plate & & & & \\
\hline \multirow[t]{2}{*}{ 4-NQO } & $0.2 \mu \mathrm{g}$ & ND & ND & ND & ND \\
\hline & $0.4 \mu g$ & $227.5 \pm 3$ & ND & ND & ND \\
\hline \multirow[t]{2}{*}{ BAP } & $5 \mu \mathrm{g}$ & ND & ND & $1430 \pm 14$ & $863 \pm 75$ \\
\hline & $10 \mu \mathrm{g}$ & ND & $459 \pm 12$ & ND & ND \\
\hline AFB1 & $0.03 \mu \mathrm{g}$ & ND & $130 \pm 21$ & ND & $241 \pm 12$ \\
\hline
\end{tabular}

${ }^{a}=$ Mean of duplicate

e=effect

$\mathrm{p}=$ partial killing effect

$\mathrm{ND}=$ Not determined 
Table 4 Summary of histopathological appearance in kidney and liver of rats

\begin{tabular}{|c|c|c|c|c|c|c|c|c|c|c|c|}
\hline \multirow[t]{2}{*}{ Organ appearance } & \multicolumn{2}{|c|}{ DG diet } & \multicolumn{2}{|c|}{ AP diet } & \multicolumn{2}{|c|}{ AL diet } & \multicolumn{2}{|c|}{ RS diet } & \multicolumn{2}{|c|}{ NT diet } & \multirow{2}{*}{$\begin{array}{l}\text { CONTROL } \\
n\end{array}$} \\
\hline & $n$ & $\mathrm{p}$ & $n$ & $p$ & $n$ & $p$ & $n$ & $p$ & $n$ & $p$ & \\
\hline \multicolumn{12}{|l|}{ Kidney } \\
\hline normal appearance & - & 0.007 & - & 0.007 & - & 0.001 & - & 0.007 & - & 0.017 & 6 \\
\hline 0-25\% tissue degenerated & 2 & & 1 & & 6 & & 2 & & 1 & & - \\
\hline $26-50 \%$ tissue degenerated & 2 & & 2 & & - & & 2 & & 3 & & - \\
\hline $51-75 \%$ tissue degenerated & 2 & & 3 & & - & & 2 & & 1 & & - \\
\hline 76-100\% tissue degenerated & - & & - & & - & & - & & 1 & & - \\
\hline Total & 6 & & 6 & & 6 & & 6 & & 6 & & 6 \\
\hline \multicolumn{12}{|l|}{ Liver } \\
\hline normal appearance & - & 0.007 & - & 0.017 & - & 0.002 & - & 0.007 & - & 0.002 & 6 \\
\hline 0-25\% tissue degenerated & 2 & & 2 & & 4 & & - & & 5 & & - \\
\hline $26-50 \%$ tissue degenerated & 1 & & 1 & & 2 & & 1 & & 1 & & - \\
\hline $51-75 \%$ tissue degenerated & - & & 2 & & - & & 4 & & - & & - \\
\hline 76-100\% tissue degenerated & 3 & & 1 & & - & & 1 & & - & & - \\
\hline Total & 6 & & 6 & & 6 & & 6 & & 6 & & 6 \\
\hline
\end{tabular}

The numbers of rats were 6 per each group. Values are significantly different at $P<0.05$ using Chi-Square test compared to control

extracts, and $10 \mathrm{mg} /$ plate for absolute ethanol extracts. On the other hand, absolute ethanol extracts exhibited strong antimicrobial activity toward S. typhimurium; this result led us to suppose that ethanol was as stronger solvent, and more mutagenic agents could be extracted. To confirm the potential effects of the diets, further in vivo studies are needed using animal models, to isolate the components of dry canine food.

Knize et al. [18] analyzed twenty-five commercial pet foods for mutagenicity activity using the Ames'/ Salmonella test with strain TA98 and added metabolic activation. Almost all gave a positive mutagenic response [18]. This may be affected from various substances contained. Dry pet food contains a number of nutrients and additive compounds. The diets also contain cooked meat. Differences might be expected by the type of meat, heating process. On the other hand, several substances related to natural antimutagenicity or anti-carcinogenicity that has simultaneously been identified as mutagenic or carcinogenic [19]. The positive findings in this study revealed the presence of mutagenic components in dry pet-food extracts, with either direct or indirect mutagenic action.

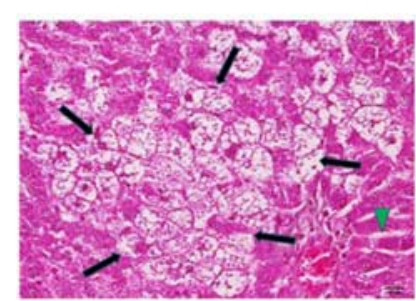

A

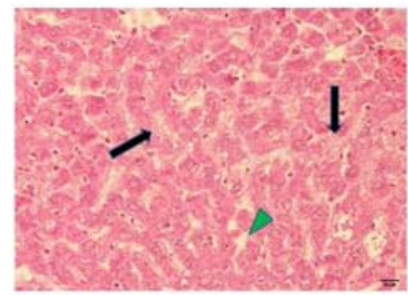

D

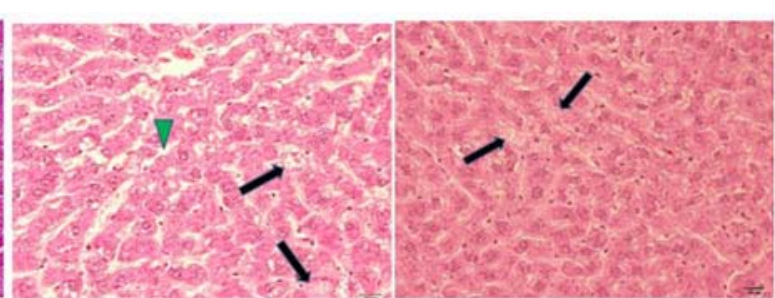

B

C

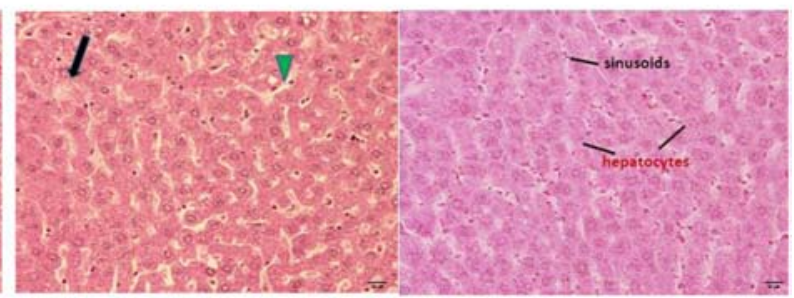

E
F

Fig. 3 Paraffin section of male rat livers with hematoxylin and eosin staining at x 40 magnification. The rats were fed with DG, AP, AL, RS and NT canine diet for 90 days. Arrows were indicating abnormal liver appearance of rats with foamy cells. Arrow heads were indicating abnormal liver appearance of rats with the dilation of sinosoids 


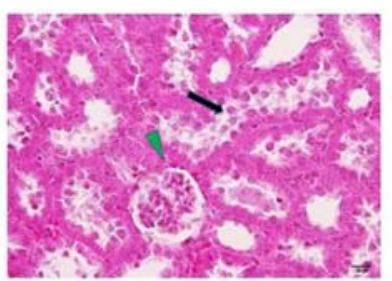

A

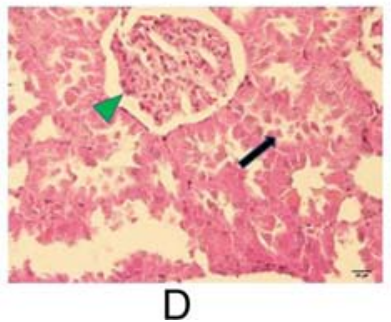

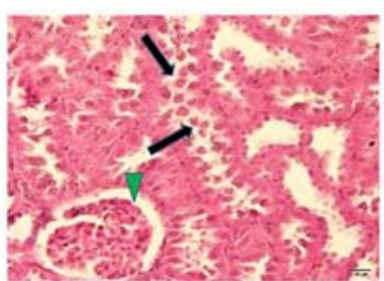

B

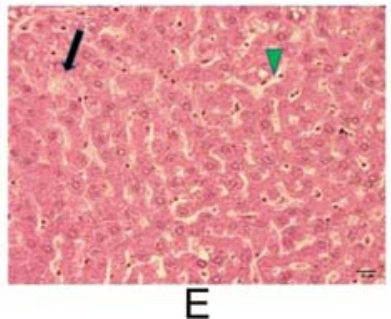

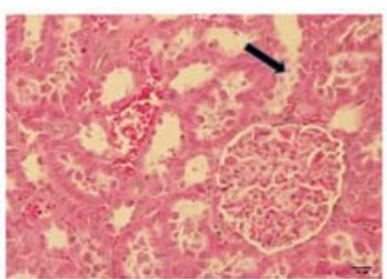

C

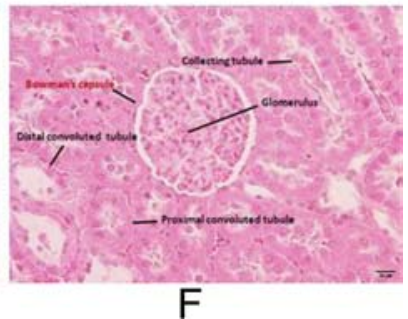

Fig. 4 Paraffin section of male rat kidneys with hematoxylin and eosin staining at $x 40$ magnification. The rats were fed with $D G$, AP, AL, RS and NT canine diet for 90 days. Arrows were indicating kidney degeneration of rats with the collapsed epithelial cells of the proximal tubules. Arrow heads were indicating kidney degeneration of rats with the congested and atrophied glomerulus

Future studies should focus on better characterization of the mutagenic and antimutagenic activities of dry pet food extracts, by using other tester strains, and identifying specifically their active compounds and modes of action.

Although no significant effect of long-term consumption of dry canine foods (for 15 weeks) in rats was observed on clinical blood chemistry, total average weight gain in some groups of rats fed commercial canine foods was higher than the control. There were also differences in clinical blood chemistry for serum BUN, CR, ALT, AST, and P, compared with the control group. This may have resulted from the different grades of dry canine foods. These are in agreement with our histopathological analysis, which showed that all 5 brands of dry canine foods induced the pathophysiological degeneration of the liver and kidney. Overconsumption of pet food may cause the change in gut bacteria. Although the underlying mechanism is not yet known, changes in microbial diversity in the intestine may potentially contribute to fat accumulation and degeneration of the liver and kidney. Some photochemicals such as ursolic acid have been reported to change the amount of gut bacteria and decrease the risk of obesity [11]. The composition of fatty acids in pet food may influence the expression of amino acids in the liver and kidney [10]. This may also be the cause of degeneration of liver and kidney. In addition to over consumption of foods, several studies reported that most canine food was contaminated with aflatoxin [20], some trace metal elements [21] and heterocyclic amine from heating process during food production [18]. All these can cause liver and kidney degeneration, due to increased rates of tissue oxidative stress and toxic chemical production [20, 21].

All rats remained alive at the end of the experimental period (15 weeks) without any externally apparent signs of toxicity. However, there were mild abnormal blood biochemistry results, and histological changes in canine food fed rats after sacrifice. No change in food intake was observed in any groups. Body weight and body weight gain appeared to not be affected. A further study is planned to investigate the toxic effects of local dry canine foods following OECD guide lines, in which acute and chronic effects analysis with varying doses and time. This would include investgating ultrastructural changes to find early degeneration in vital organs. Moreover, a cohort study with dogs could provide further explanation of the dynamics over time.

\section{Conclusions}

Mutagenic potential was found in all local-brand dry canine foods tested, and the potential health impacts of long-term consumption in rats were observed. Thus, the dog owner should be aware of their commercial dog food choices or alternatively feed their dog with fresh food. Further mutagenicity testing and identification of toxic substance contamination in the diet should be conducted, to elucidate the safety of locally manufactured, generic-brand, dry canine foods.

\section{Abbreviations}

$A F B_{1}$ : Aflatoxin $B_{1} ; A_{F B}$ : Aflatoxin $B_{2 a} ; A L T$ : Alanine aminotransferase; AMS: Analyzer Medical System; AST: Aspartate aminotransferase; B(a)P: Benzo(a)pyrene; BUN: Blood urea nitrogen; CHOL: Cholesterol; 
CR: Creatinine; Hb: Hemoglobin; Hct: Hematocrit; LSD: Least Significant Different; MCH: Mean corpuscular hemoglobin; MCHC: Mean corpuscular hemoglobin concentration; NQO: 4-Nitroquinoline 1-oxide; P: Phosphorus; TG: Triglyceride; US: United States; WBC: White blood cells.

\section{Competing interests}

The authors declare that they have no competing interests.

\section{Authors' contributions}

TK performed mutagenicity assay, animal experiments and reported the data. AT provided and advised mutagenicity technique. SK provided and advised the technique animal experiments. PP analyzed pathological and histological examinations. SP assisted in mutagenicity assay and animal experiments. UC analyzed pathological, histological examinations. PM performed blood chemical test. KK designed the study, analyzed the data and wrote the manuscript. All authors read and approved the final manuscript.

\section{Acknowledgements}

This study was funded by Kasetsart University. The authors would also to thank the staff of the Department of Tropical Nutrition and Food Science and the Laboratory Animal Unit, Faculty of Tropical Medicine, Mahidol University, for their kind cooperation.

\section{Author details}

'Department of Tropical Nutrition and Food Science, Faculty of Tropical Medicine, Mahidol University, Bangkok 10400, Thailand. 'Department of Tropical Pathology, Faculty of Tropical Medicine, Mahidol University, Bangkok 10400, Thailand. ${ }^{3}$ Department of Pathology, Faculty of Veterinary Medicine, Kasetsart University, Bangkok 10900, Thailand.

Received: 23 September 2015 Accepted: 14 January 2016

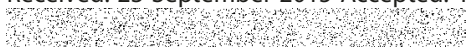

\section{References}

1. Markwell PJ, Erk W, Parkin GD. Obesity in the canine. J Small Anim Pract 1990;31:533-7

2. Bray GA. Obesity is a chronic, relapsing neurochemical disease. Int J Obes 2004;28:34-8.

3. Butterwick RF, Hawthorne AJ. Advances in dietary management of obesity in dogs and cats. J Nutr. 1998;128(Suppl):2771-5.

4. Stogdale L. Definition of diabetes mellitus. Cornell Vet. 1986;76:156-74

5. He Q, Ren P, Kong X, Wu Y, Wu G, Li P, et al. Comparison of serum metabolite compositions between obese and lean growing pigs using an NMR-based metabonomic approach. J Nutr Biochem. 2012;23:133-9.

6. Morris Animal Foundation. Animal health survey. Englewood. 1991.

7. Sonnenschein EG, Glickman LT, Goldschmidt MH, Mckee LJ. Body conformation, diet, and risk of breast cancer in pet dogs: a case-control study. Am J Epidemiol. 1991;133:694-703.

8. Anonymous. Thai Farmers Bank. 2001;7:935.

9. Anuwong W. Pet foods: growth opportunities amidst crises and beyond. Pet foods forum asia. 16th ed. 2012

10. Feng Z, Zhou X, Wu F, Yao K, Kong X, Li T, et al. Both dietary supplementation with monosodium L-glutamate and fat modify circulating and tissue amino acids pools in growing pigs, but with little interactive effect. PLoS ONE. 2014;9(1):e84533.

11. Feng Z, Wu C, Zhou J, Wu F, Li J, Li T, et al. Disturbance of the intestinal microbial community by ursolic acid contributes to its function as a regulator of fat deposition. J Funct Foods. 2015;14:456-68.

12. Maron DM, Ames BN. Revised methods for the Salmonella mutagenicity test. Mutat Res. 1983;113:173-251.

13. Gad SC, Chengelis CP. Acute toxicology testing. 2nd ed. California: Academic; 1998

14. Zeiger E. Identification of rodent carcinogens and non-carcinogens using genetic toxicity tests: premises, promises, and performance. Regul Toxicol Pharm. 1998;28:85-95.

15. Mortelmans K, Zeiger E. The Ames Salmonella/microsome mutagenicity assay. Mutat Res. 2000;445:29-60.

16. Ferguson $L R$, Denny WA. Anticancer drug and underestimated risk or an underutilized resource in mutagenesis? Mutat Res. 1995;331:1-26.

17. Strauss BS. Frameshift mutations, microsatellites and mismatch repair. Mutat Res. 1999;437:195-203.
18. Knize MG, Salmon CP, Felton JS. Mutagenic activity and heterocyclic amine carcinogens in commercial pet foods. Mutat Res. 2003:539:195-201.

19. Franke SIR, Ckless K, Silveira JD, Rubensam G, Brendel M, Erdtmann B, et al. Study of antioxidant and mutagenic activity of different orange juices. Food Chem. 2004;88:45-55.

20. Sharma M, Márquez C. Determination of aflatoxins in domestic pet foods (dog and cat) using immunoaffinity column and HPLC. Anim Feed Sci Tech. 2001;93:109-14.

21. Duran A, Tuzen M, Soylak M. Trace element concentrations of some pet foods commercially available in Turkey. Food Chem Toxicol. 2010;48:2833-7.

\section{Submit your next manuscript to BioMed Central and we will help you at every step:}

- We accept pre-submission inquiries

- Our selector tool helps you to find the most relevant journal

- We provide round the clock customer support

- Convenient online submission

- Thorough peer review

- Inclusion in PubMed and all major indexing services

- Maximum visibility for your research

Submit your manuscript at www.biomedcentral.com/submit
Biomed Central 